\title{
Orthographic Constraints on the Integration of English Loanwords in Mandarin Chinese
}

\author{
Feiyang Tian \\ Foreign Languages Department, Beijing University of Aeronautics and Astronautics, Beijing, China \\ Email: F.Tian@uvt.nl
}

\begin{abstract}
Chinese loan words of English origin can be roughly divided into three groups: phonemic loan, semantic loan and combination of the above two. This paper gives a brief sketch of the three different kinds of loanwords and goes a step further to point out that semantic loan tends to be the eventual form of adaptation for words borrowed from English, for the reasons that Chinese is monosyllabic, Chinese writing system is morphemic, and has little to do with its sound system, etc. Therefore, direct replication of the pronunciations of English words (phonemic loan or transliteration in this sense) is not compatible with the coding structure of Chinese. It tends to be replaced by loan translation or semantic loans. To support this hypothesis, this paper presents a data-based analysis of 55 borrowed lexical items as found in 80 articles from a Chinese newspaper and a magazine. The findings show that transliterated loanwords are not as well-accepted as semantic loans in Chinese and usually are replaced by the latter.
\end{abstract}

Index Terms - transliteration, phonemic loan, semantic loan, loan translation, integration, constraint

\section{INTRODUCTION}

Chinese is the language that has the largest number of speakers in the world. English, the international lingua franca, is probably the only "world language" in the field of politics, entertainment, pop culture and technology. Interaction between these two "giant" languages is becoming ever more intense under the present situation of social-economic and technological communication. The result is language change. Lexical borrowing, one of the important aspects of language change, is the focus of the present paper.

When English words enter into Chinese, most of them undergo adaptations. The adaptation of a loanword demands to preserve certain information from the source word while still satisfying the constraints that make the lexical item sound like a word of the recipient language (Kager, 1999). The present paper focuses on the constraints on loanwords' assimilation in Chinese. It is to be observed from a comparison between different types of loanwords in Chinese, namely, phonemic loan, semantic loan and the combination of the two. It puts forward a hypothesis that Chinese adapts foreign words primarily via loan translation due to certain typological as well as orthographic constraints. To testify this, a small-scale qualitative and also a quantitative research are carried out.

\section{Cllassification OF LOANWORDS IN MANDARIN Chinese}

While analyzing different layers of loanwords in Mandarin Chinese, it is necessary first to describe all their main types. To solve this problem, I choose to apply the principles offered by Einar Haugen (1950) who divides borrowings into 3 main types:

(1) Loanwords show morphemic importation without substitution.

(2) Loan blends show morphemic substitution as well as importation.

(3) Loan shifts show morphemic substitution without importation.

Haugen's first type of loanwords implies borrowing of both the meaning and morphemes of a word from a donor language, i.e. a loanword which is completely adopted by the recipient language without any substitution with the native morphemes. This is equivalent to phonemic loans in Mandarin Chinese. Haugen's second type refers to borrowing with partial substitution with native morphemes and equals to hybrid loanwords, while his third type, morphemic substitution without importation, implies only the meaning of the original word is adopted while all its morphemes are substituted with the native morphemes. In Chinese, this is equivalent to loan translation or semantic loan.

The present study concentrates on the first and the third type while combines the second type, loan blend, with the first type since both of them involves importation and importation is their most prominent characteristic, especially when considering Chinese loanwords borrowed from English. Furthermore, such a classification facilitates the argumentation of loanwords' integration into Chinese in the following part. Another type, a mingling of phonemic and semantic loans, is added as the third type.

A. Phonemic Loan (Transliteration) 
Phonemic loans or transliterated loanwords in Mandarin Chinese refer to words that are phonologically similar both in English and Chinese. They are used in Chinese with the closest possible sound and the closest possible meaning to the original word. For example, Chinese "mai ke feng" is basically identical to English "microphone" and is used in the same context. In the writing system, “mai ke feng” is represented as “麦克风”. The three characters mean "wheat, gram, and wind" respectively. They are just combined together to imitate the sound of the English word. Another example is the English word "fan" whose Chinese equivalent is /fen si/ (the sound is itself an imitation of the plural form "fans"), the Chinese characters chosen to represent the sound is “粉丝” which refers to a kind of noodle like food. Sometimes this can be very confusing for beginning Chinese readers who cannot immediately realize that one should read just the sound and ignore the meaning. What's more, to transcribe the sounds of foreign words, Chinese has also coined some characters that do not mean anything. For instance, "coffee" in Chinese is /ka fei/ represented in the writing system as “咖啡”. These two characters do not have any specific meaning in Chinese, they are just coined to symbolize the sound of the English word.

\section{B. Semantic Loan}

A semantic loan is a process of borrowing semantic meaning rather than lexical items from another language, very similar to the formation of loan translation.

The present study treats loan translation as a type of semantic loan because the mechanism that produces a semantic loan is very similar to that of a loan translation, being a process of borrowing semantic meaning from another language. Loan translation (also known as "calque"), in its narrow definition, refers to word-for-word (or morpheme-for-morpheme) translations of some foreign words or expressions. Here, the actual word (i.e. phonological shape) from the donor language is not borrowed; instead, how that language conveys a particular notion is borrowed. What happens, then, is that the recipient language uses its own word to convey the desired notion of the donor language word (Myers-Scotton, 2006). In Chinese, it means to create a compound word that actually translates the concept behind the borrowed word. For example, English "blueprint" is known as /lan tu/(蓝图, literally means blue+ picture), "flagship" is /qi jian/(旗舰, flag+ship), and "bottleneck" is /ping jing/ (瓶颈, bottle+neck). There are also many English words calqued from Chinese, such as “running dog” is from Chinese 走狗(/zou gou/), “lose face” from Chinese 丢脸 (/diu lian/), and “long time no see” from Chinese 好久不见(/hao jiu bu jian/), etc.

\section{Combination of Phonemic and Semantic Loans (Phono-semantic Matching)}

Besides transliteration and loan translation, there exists another type of loanwords, the combination of phonemic and semantic loans, or phono-semantic matching, as Zuckermann (2003a) calls it. Phono-semantic matching is distinct from calquing. While calquing includes semantic translation, it does not consist of phonetic matching (i.e. retaining the approximate sound of the borrowed word through matching it with a similar-sounding pre-existent word/morpheme in the target language). Words borrowed in this way are not only phonologically similar in English and Chinese, but the Chinese characters selected to represent the sound has also the similar meaning with the original word. For example, Coca Cola in Chinese is 可口可乐/ke kou ke le/, which translates literally as "tasty, can make you happy". Besides, there are words which not only have a perfect combination of sound imitation and meaning representation in the writing system, but with very creative and imaginative meanings in the choice of Chinese characters. For example, English "miniskirt" in Chinese is 迷你裙/mi ni qun/, the three characters literally mean "attract you skirt." As Myers-Scotton (2006) points out: "Speakers try to find Chinese characters that stand for a similar reference to the borrowed words. But speakers also want the characters to sound like the borrowed word. They end up with some very imaginative ways of accommodating a borrowed word..." words she gives as examples are shown in table-1:

TABLE-1

EXAMPLES MYERS-SCOTTON GIVES AS PHONO-SEMANTIC MATCHING

\begin{tabular}{|c|l|l|}
\hline Original Forms & $\begin{array}{l}\text { Translation Forms } \\
\text { (Character /Pinyin Form) }\end{array}$ & $\begin{array}{l}\text { Word-by-word Equivalent } \\
\text { Meanings in English }\end{array}$ \\
\hline Benz & 奔驰/ben chi/ & run race \\
\hline Benz-Mercedes & 宝马/bao ma/ & treasure horse \\
\hline gene & 基因/ji in/ & basic element \\
\hline vitamin & 维他命/wei ta ming / & keep his life \\
\hline
\end{tabular}

This kind of loanwords usually appears in brand names for commercial purpose. Their occurrence is largely coincident. Therefore, they do not account for much in the loan words family. Among these three types, semantic loans or loan translation seem to be more popular. The reason why it is more easily accepted by Chinese has to do with language structure and orthographic constraints which are to be explained in the following part.

\section{ORTHOGRAPHIC CONSTRAINTS ON THE INTEGRATION OF ENGLISH LOANWORDS INTO CHINESE}

By orthographic constraints, we mean that Chinese writing system, as compared with the English alphabetic orthography, may have played a role in the integration of English loanwords. When an English word is borrowed into 
Chinese, it first undergoes phonological changes to sound like Chinese. Then, certain Chinese characters will be selected to represent the sound. It is the choice of Chinese characters that pose much of the problems. Zuckerman (2003a) points out: "In Chinese, it is impossible to import the Anglicism as it stands, for example by morpho-phonemic adaptation. One can calque the Anglicism or neologise, but----at least in writing----one cannot import the sound without using indigenous characters...the use of Chinese characters is a necessity."

A transliterated English loanword which emphasizes sound imitation and overlooks the similarity between the meaning of the original word and the meaning of characters selected to symbolize the sound usually sounds strange to native Chinese speakers, especially to monolinguals who are not familiar with English sounds.

The writing system of Chinese is unique in that it is primarily pictographic and ideographic and has little or almost nothing to do with its sound system. By "pictographic", we refer to characters such as 山(mountain)and 火(fire)which are originally pictures of the objects they denote, whereas “ideographic" refers to characters such as 明（bright）which is composed of two radicals meaning respectively the sun and the moon, and the whole character meaning brightness. Therefore, unlike alphabetic orthography, each Chinese character is a self-contained unit of form, sound and meaning. In native speakers' minds, there is a strict correspondence between syllable, character and meaning. That is to say, a syllable has a meaning and a meaning is represented with a character. Zuckermann (2003a), after studying the Chinese writing system, concludes that it is multifunctional: pleremic ("full" of meaning, e.g. logographic), cenemic ("empty" of meaning, e.g. phonographic) and simultaneously cenemic and pleremic (phono-logographic). He argues that Bloomfield's assertion that "a language is the same no matter what system of writing may be used" is inaccurate. "If Chinese had been written using roman letters, thousands of Chinese words would not have been coined, or would have been coined with completely different forms(Zuckermann, 2003b )."

After thousands years of evolution, pictographic characters do not constitute a large part of Chinese characters, however, the habit of writing and recognizing script forms in terms of images has evolved into a cognitive process that is deep-rooted in Chinese people's minds. This cognitive process----thinking, writing and decoding in terms of images have long been interacting and reinforcing one another for thousands of years, and, as a result, have played a significant role in shaping Chinese culture and Chinese mind(Jia \& Jia, 2005). A question Chinese people frequently ask when hearing an unfamiliar word is: "which character do you refer to?" Therefore, when an English word, with its original sound and meaning, enters into Chinese, it, first of all, has to be processed in Chinese people's mind, analyzed as meaningful characters and then decided whether it can be accepted or not. When it turns out to be that the combination of the several characters that make up an English word does not make any sense in Chinese, the word will most probably be replaced by a semantic loan or loan translation or simply be discarded.

\section{DATA}

\section{A. A Qualitative Study}

The data in this study were collected from a Chinese newspaper, Beijing Youth Daily and a Chinese magazine, Beijing Youth Weekly. The Beijing Youth Daily is the official newspaper of the Communist Youth League Committee in Beijing. It is one of Beijing's most widely-circulated newspapers, publishing an average of 50 pages a day in 32 provinces. Similar to major newspapers in any language with a national circulation, Beijing Youth Daily has a great deal of coverage of important events in China and around the world. Beijing Youth Weekly, likewise, targets primarily the young readers in Beijing. It features shopping, travel, performances, and various aspects of pop culture in Beijing. It consists of three different sections, "focus", "life" and "entertainment". It is considered that the loanwords found in this newspapers and magazine represent Chinese borrowings from English, in vocabulary as well as in grammar, which was mainly why this newspaper and magazine were chosen.

The data were obtained from articles published in Beijing Youth Daily and Beijing Youth Weekly, in August, September, October, November and December 2011. The days for data collection were randomly decided. In Beijing Youth Daily, articles were selected from all but the Sports Section which was felt least likely to contain loanwords. In Beijing Youth Weekly, articles were selected from all the sections. For both the newspaper and the magazine, the data were obtained from the electronic versions on their websites. The headlines were scanned first. If the headline suggested that the article might have lexical items borrowed from English, the article was downloaded and became part of the data. Usually only one article was selected from any section in one issue. The data thus collected contain approximately 80 articles. Approximately 47 articles were taken from Beijing Youth Daily, and 33 articles from Beijing Youth Weekly. The 80 articles contain a total of 55 loanwords. A list of all the items is given in the appendix.

The following observations can be made about loanwords found in the above mentioned newspaper and magazine. First, the number of transliterated words and loan translations is roughly the same, which is not in line with our assumption that there are more loan translations than transliterations. However, this does not necessarily mean that our assumption is wrong, but certain social psychological reasons are involved, which are to be explained in the following. Second, the number of loanwords found in the newspaper and the magazine is also roughly the same, which testifies our decision in choosing this newspaper and magazine as our source of samples. Finally, as expected, cases of combination of phonemic and semantic translations are mostly brand names.

\section{B. A Quantitative Study}


After the above-mentioned small-scale qualitative study, we did a quantitative research, using a database called National Broadcast Media Language Resources on Line, a large-scale dynamic and diachronic broadcast media language monitoring corpus which includes different periods of radio and TV multimodal database. In order to examine the use and frequency of all the listed borrowed lexical items, we typed in all those borrowed words and defined the time period to be from January 2004 to December 2010, hence got the frequency of these words. Table-2 is a comparison between the type of loanwords which is most frequently used and the type which is least frequently used.

TABLE-2

FREQUENCY OF DIFFERENT TYPES OF LOANWORDS

\begin{tabular}{|c|c|c|c|}
\hline \multicolumn{2}{|c|}{$\begin{array}{l}\text { Most frequently used loanwords(with their time of appearance } \\
\text { in the corpus) }\end{array}$} & \multicolumn{2}{|c|}{$\begin{array}{l}\text { Least frequently used loanwords(with their time of appearance in the } \\
\text { corpus) }\end{array}$} \\
\hline transliteration & Loan translation & transliteration & Loan translation \\
\hline $\begin{array}{l}\text { Typhoon,台风 (/tai feng/) } \\
4341\end{array}$ & Hot-line, 热线(/re xian/),9775 & Rally, 拉力赛(/la li sai/), 100 & Generation gap,代沟(/dai gou/),33 \\
\hline $\begin{array}{l}\text { Aides, 艾滋病(/ai zi } \\
\text { bing/), } 1550\end{array}$ & $\begin{array}{l}\text { Super-market,超市(/cha } \\
\text { shi/),4903 }\end{array}$ & Bikini, 比基尼(/bi ji ni/),55 & Soap opera, 肥㿝剧(/fei zao ju/),19 \\
\hline \multirow[t]{6}{*}{ Fans,粉丝(/fen si/), 874} & $\begin{array}{l}\text { Legal person, 法人(/far } \\
\text { en/), } 1542\end{array}$ & $\begin{array}{l}\text { Mosaic, 马赛克(/ma sai ke/), } \\
45\end{array}$ & $\begin{array}{l}\text { Bachelor mother, 单身母亲(/dan shen } \\
\text { mu qin/),14 }\end{array}$ \\
\hline & $\begin{array}{l}\text { Low-carbon, 低碳 (/di } \\
\tan /), 1518\end{array}$ & $\begin{array}{l}\text { Elnino, 厄尔尼诺(/e er ni } \\
\text { nuo/),39 }\end{array}$ & \\
\hline & Mini-blog,微博(/wei bo/), 1030 & Bungee, 蹦极(/beng ji/),30 & \\
\hline & $\begin{array}{l}\text { White-collar,白领(/bai } \\
\text { ling/),968 }\end{array}$ & $\begin{array}{l}\text { Hula loop, 呼啦圈(/hu la } \\
\text { quan/), } 15\end{array}$ & \\
\hline & Cold war, 冷战(/leng zhan/),905 & Laser, 镭射(/lei she/), 15 & \\
\hline & $\begin{array}{l}\text { Bottle- neck,瓶颈(/ping } \\
\text { jing/),715 }\end{array}$ & Punk, 朋克(/peng ke/),6 & \\
\hline
\end{tabular}

Things that are noteworthy about the result of this corpus investigation are as follows. First, the number of loan translations which are frequently used is more than that of transliterations. Here, the criteria to judge whether a word is frequently used or not is arbitrarily defined as the time of appearance in the corpus to be over 700. Altogether, there are 8 loan translations that occur more than 700 times in the corpus whereas only 3 transliterations that meet this standard. What can be implied is: loan translations, compared with transliteration, are well-accepted and more frequently used in modern Chinese. In addition, among the three frequently used transliterated words, there are 粉丝(fans)which does not completely belong to transliterations because 粉丝 is a Chinese word which already exists and refers to a kind of noodle-like food. The extension of its meaning to enthusiasts has some special pragmatic effects which may explain its high frequency in the corpus. However, we still place it in the category of transliteration because elements of phonemic translation involved in its appearance in Chinese are more prominent. The other two transliterated words that have a relatively high frequency are 台风(typhoon) and 艾滋病 (aids). Their high frequency can be explained through the fact that healthcare and world climate change are among the hot topics in these years' news report.

Second, the number of least frequently used transliterated words is more than that of loan translations. Here, the criterion to judge whether a word is infrequently used is arbitrarily defined as the appearance in the corpus to be less than 100. There are 8 transliterated words which meet this standard while only 3 loan translations. Obviously, there are more transliterated words that are not well-assimilated in Mandarin Chinese.

Third, the average frequency of loan translations is higher than that of transliterations, which provides further evidence that loan translations are more easily integrated in Chinese than transliterations. In other words, transliterations do not last long and is likely substituted with other words.

Last but not least, some of the transliterated words, but none of the loan translations in the data occur with typographic flagging and metalinguistic commentary. Typographic markings include italics, boldface, or quotation marks, while metalinguistic commentary usually translates or explains a term. Both of them indicate that the loanword is used infrequently and probably restricted to bilingual speakers and at the beginning of the borrowing process (Field, 2002).

\section{More Evidence}

Besides these observations from the corpus investigation which in some degree attest our hypothesis that loan translation tends to be the last form of adaptation for English words borrowed into Chinese, there is an interesting phenomenon that provides further evidence. Some English words have two versions of Chinese translation, one of them transliteration while the other loan translation or semantic loan. When these words are first borrowed, they take the form of transliteration, after a period of time, this transliterated version is replaced by a semantic loan, and in between, there is a period when people just hesitate as to which version of the words they should use. Examples are as follows in table-3: 
TABLE-3

LOANWODS THAT HAVE TWO VERSIONS OF TRANSLATION IN CHINESE

\begin{tabular}{|l|l|l|l|}
\hline Original Form & $\begin{array}{l}\text { Translation Form 1 } \\
\text { (Character /Pinyin) }\end{array}$ & $\begin{array}{l}\text { Translation Form 2 winning more } \\
\text { popularity today (Character/Pinyin) }\end{array}$ & $\begin{array}{l}\text { Literal Meaning of Translation } \\
\text { Form 2 }\end{array}$ \\
\hline microphone & 麦克风/mai ke feng/ & 话筒/hua tong/ & loud speaker \\
\hline e-mail & 伊妹儿/yi mei er/ & 电子邮件/dian zi you jian/ & electronic letter \\
\hline SARS & 萨斯/sa si/ & 非典/fei dian/ & non-typical \\
\hline Buffet & 簿飞/bu fei/ & 自助/zi zhu/ & help oneself \\
\hline laser & 镭射/lei she/ & 激光/ji guang/ & a special ray \\
\hline copy & 拷贝/kao bei/ & 复制/fu zhi/ & duplicate \\
\hline
\end{tabular}

More examples can be found in words from the May Fourth period. The May Fourth Movement was an anti-imperialist, cultural, and political movement growing out of student demonstrations in Beijing on May 4, 1919, protesting the Chinese government's weak response to the foreign intruders. This is also a period in Chinese history where the interaction of Western and Eastern civilizations became ever more intensive and made a tremendous influence on the Chinese society and Chinese language as well. In the process of imitating and learning West, large amounts of English words were imported into Chinese, most of them presented in the form of phonemic translation and most of them were later replaced by semantic loans (Mavromatis, 2009). As is shown in table-4:

TABLE-4

WORDS BORROWED DUING THE MAY FOURTH PERIOD

\begin{tabular}{|c|c|c|}
\hline The original English word & Transliterated form in May Forth Period & $\begin{array}{l}\text { Present form in modern Chinese/literal } \\
\text { meaning of translation }\end{array}$ \\
\hline bank & 版克（/ban ke/） & 银行(/yin hang/), silver bank \\
\hline democracy & 德莫克利西(/de mo ke li xi/) & 民主(/min zhu/),ruled by people \\
\hline science & 赛因斯(/sai yin si/) & 科学(/ke xue/), ology \\
\hline cement & 水门汀 (/shui men ting/) & 水泥(/shui ni/), water mud \\
\hline Telephone & 德律风(/de lv feng/) & 电话(/dian hua/),electronic speech \\
\hline grammar & 格朗玛(/ge lang ma/) & 语法(/yu fa/),law of language \\
\hline violin & 梵华玲(/fan hua ling/) & $\begin{array}{l}\text { 小提琴(/xiao ti qin/), little musical } \\
\text { instrument that can be carried }\end{array}$ \\
\hline seminar & 塞米纳尔(/sai mi na er/) & 讨论会 (/tao lun hui/) discussion \\
\hline mister & 密司脱（/mi si tuo/） & 先生 (/xian sheng/),gentleman \\
\hline
\end{tabular}

However, despite the typological and orthographic constraints, there exist a considerable amount of transliterated words which, like loan translations, are also well established in Mandarin Chinese. This is probably due to social-psychological factors that are to be discussed in the following.

\section{A Counter Force: Socio-psychological Tendency}

The use of English loan words may serve to indicate social status. Words from languages associated with high social-economic status sound fashionable, so being able to pronounce them in a way approximating their original form gives the speaker a certain prestige (Myers-Scotton, 2006). Therefore, we see words transliterated into Chinese which are relatively long and which contain several Chinese characters. For example, the English word "outlets" in Chinese is 奥特莱斯/ao te lai si/. Among the four characters selected to represent the English sound, 奥/ao/ and 莱/lai/ are coined characters which has no specific meaning and can only be taken as alphabet-like signs, while 斯/si/ in ancient Chinese, means "this" and is seldom used in modern Chinese, only 特/te/ is a modern Chinese morpheme which means “special”. So 奥特莱斯 can be regarded as a typical example of transliteration. Its popularity in modern Chinese is a result of "prestige" tendency as mentioned above.

Similarly, another result of the "prestige" tendency of the English influence on Chinese is the appearance in modern Chinese of so-called "lettered words" which are spelled with letters from foreign alphabets. This has appeared in magazines, newspapers, on web sites and on TV, such as U 盘 (USB), IT 业, WTO, GDP, etc. there are even some lettered words that do not come from English, but from Pinyin(Chinese alphabet), such as HSK(han yu shui ping kao shi, 汉语水平考试, Test of Chinese Language proficiency).

The existence of these transliterated loanwords and the appearance of "lettered words" can also be regarded as the result of the widespread of bilingualism. Bilingual members of the speech community, who are aware of the English pronunciation, make an effort to authenticate the borrowed word by replicating its original phonology. Then, this replication of the words' original pronunciation is imitated by monolinguals out of intentions to try to look fashionable or well-educated, etc. However, we can also be bold enough to say that at least, some of these transliterations will eventually be replaced by loan translations because the force of language structure constraints is more powerful than that of socio-psychological tendency. And Chinese do not accept polysyllabic words whose components cannot be analyzed as meaningful sounds. Probably the word 奥特莱斯, in the coming future, will be replaced by 直销店/zhi xiao dian(literally meaning a direct sale shop), 工厂店/gong chang dian(literally meaning a factory shop) or 打折村 
Ida zhe cun(literally meaning a discount village), etc. As a matter of fact, some Chinese have already began to use such terms instead of 奥特莱斯.

\section{CONCLUSION}

English loan words, when entering Chinese, are first modified phonologically to sound like Chinese, and then certain Chinese characters are selected to represent the sound, sometimes the choice of characters can be a perfect combination of meaning and sounds, i.e. not only preserves the sound but the meaning of the original English word. However, this case of coincidence seldom happens. In most cases, English loans are transliterated into Chinese which tend to be replaced by loan translations. The reason behind this tendency is mainly orthographic. Opposite to this, there is also a "prestige" tendency that facilitates the absorption of English sounds.

English, being the "world language", is exerting its influence over most languages in the world. However, its impact on the Chinese language is relatively weak due to the differences in their coding systems. It appears that Chinese is hard to be acculturated and will remain robust in the face of global English.

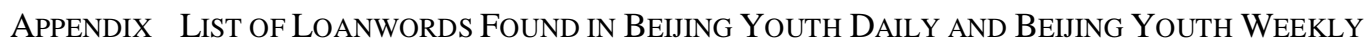

\begin{tabular}{|c|c|c|}
\hline Transliterations & Loan translations & $\begin{array}{l}\text { Combination of the two } \\
\text { Word-by-word Equivalent Meanings in } \\
\text { English }\end{array}$ \\
\hline Bungee, 蹦极（/beng ji/） & legal person,法人（/fa ren/） & Hacker,黑客(/hei ke/), black guest \\
\hline hula loop, 呼啦圈（/hu la quan/） & $\begin{array}{l}\text { bachelor mother,单身母亲（/dan shen } \\
\text { mu qin/） }\end{array}$ & $\begin{array}{l}\text { Shampoo, 香波(/xiang bo/), fragrant } \\
\text { waves }\end{array}$ \\
\hline Party,派对（/pai dui/） & dark horse, 黑马（/hei ma/） & Shock, 休克(/xiu ke/),rest overcome \\
\hline Outlets, 奥特莱斯（/ao te lai si/） & $\begin{array}{l}\text { negative growth, 负增长 (/fu zeng } \\
\text { zhang/) }\end{array}$ & Lace,蕾丝(/lei si/),bud silk \\
\hline Radar,雷达（/lei da/） & official website, 官网（/guan wang/） & $\begin{array}{l}\text { Pamper,帮宝适(/bang bao shi/),help } \\
\text { baby comfortable }\end{array}$ \\
\hline Model, 模特 (/mo te/) & $\begin{array}{l}\text { High-tech park,高科技园(/gao ke ji } \\
\text { yuan/) }\end{array}$ & Johnson 强生(/qiang sheng/),strong life \\
\hline rally race, 拉力赛（/la li sai/） & generation gap,代沟（/dai gou/） & $\begin{array}{l}\text { Mazda 马自达(/ma zi da/),horse reach } \\
\text { himself }\end{array}$ \\
\hline Fans, 粉丝 (/fen si/) & hot-line, 热线 (/re xian/) & $\begin{array}{l}\text { Playboy,花花公子(/hua hua gong } \\
\text { zi/),dandy, a man about town }\end{array}$ \\
\hline cool 酷 $(/ \mathrm{ku} /)$ & cold war,冷战（/leng zhan/） & Show, 秀 $(/$ xiu/ $)$,elegant \\
\hline Copy,拷贝（/kao bei/） & white collar,白领（/bailing/） & $\begin{array}{l}\text { carnivore, 嘉年华 (/jia nian hua/), good } \\
\text { year party }\end{array}$ \\
\hline Sauna,桑拿（/sang na/） & silicon valley 硅谷（/gui gu/） & $\begin{array}{l}\text { Gucci, 古奇 (/gu qi/), ancient and } \\
\text { special }\end{array}$ \\
\hline Elnino, 厄尔尼诺（/e er ni nuo/） & $\begin{array}{l}\text { test-tube baby,试管婴儿 (/shi guan ying } \\
\text { er/) }\end{array}$ & $\begin{array}{l}\text { Carrefour, 家乐福(/jia le fu/), family } \\
\text { happy luck }\end{array}$ \\
\hline Typhoon,台风（/tai feng/） & data bank 数据库 (/shu ju ku/) & $\begin{array}{l}\text { Beatles, 披头士 (/pi tou shi/) men whose } \\
\text { hair hang down loosely }\end{array}$ \\
\hline Mosaic,马赛克（/ma sai ke/） & supermarket 超市（/chaos hi/） & \\
\hline aids 艾滋病（/ai zi bing/） & low-carbon,低碳（/di tan/） & \\
\hline Punk,朋克 (/peng ke/) & Superstar,超星（/chao xing/） & \\
\hline Laser,镭射（/lei she/） & call girl,应招女郎（/ying zhao nv lang/） & \\
\hline Pudding, 布丁(/bu ding/) & Flagship,旗舰（/qi jian/） & \\
\hline Bikini,比基尼（/bi ji ni/） & Bottleneck,瓶颈（/ping jing/） & \\
\hline Bazzar,芭莎（/bas ha/） & blue-collar,蓝领（/lan ling/） & \\
\hline \multicolumn{3}{|l|}{ Clone,克隆（/ke long/） } \\
\hline share, 晒 (/shai/) & & \\
\hline
\end{tabular}

\section{ACKNOWLEDGMENT}

This work was supported by the 2011 Fundamental Research Funds for the Central Universities in China and by the Special Fund of Beijing Municipal Commission of Education for Co-Sponsored Projects.

\section{REFERENCES}

[1] Field, W. F. (2002). Linguistic Borrowing in Bilingual Context. Amsterdam: John Benjamin’s Publishing Company.

[2] Hannas, W. (1997). Asia's Orthographic Dilemma. Honolulu: University of Hawai'i Press.

[3] Haugen, E. (1950). The Analysis of Linguistic Borrowing. Language 26.2, 210-231.

[4] Jia,Y. \& J. Xuerui. (2005). Chinese Characters, Chinese Culture and Chinese Mind. Intercultural Communication Studies 14.1, 
152-153.

[5] Kager, R.(1999). Optimality Theory. Cambridge: Cambridge University Press.

[6] Matras, Y. (2009). Language Contact. New York: Cambridge University Press.

[7] Mavromatis, T. (2009). The Study on the Changes in Chinese Reflected in the "New Youth" Magazine during the May Fourth Period. Tamkang University, Master's degree thesis.

[8] Myers-Scotton, C. (2006). Multiple Voices: an introduction to Bilingualism. Oxford: Blackwell Publishing Ltd.

[9] Yang, J. (2005). Lexical Innovations in China English. World Englishes 24. 4, 425-436.

[10] Zuckermann, G. (2003a). Language Contact and Globalization: The Camouflaged Influence of English on the World's Languages--with special attention to Israeli and Mandarin. Cambridge Review of International Affairs 16.2, 287-309

[11] Zuckermann, G.(2003b). Language Contact and Lexical Enrichment in Israeli Hebrew. Houndmills: Palgrave Macmillan

Feiyang Tian is a lecturer of English Studies at the Department of Foreign Languages, Beijing University of Aeronautics and Astronautics, China. She is currently a Ph.D. candidate in Sociolinguistics at the School of Humanities, Tilburg University, the Netherlands. Her research interests include applied linguistics, language contact and language variation. 